\title{
Use of anti-inflammatory therapy and asthma mortality in Japan
}

\author{
S. Suissa, P. Ernst
}

Use of anti-inflammatory therapy and asthma mortality in Japan. S. Suissa, P. Ernst. (C) ERS Journals Ltd 2003.

ABSTRACT: Asthma treatment guidelines were introduced in Japan in the 1990s, insisting as elsewhere, on the importance of anti-inflammatory therapy. The present study assessed whether use of anti-inflammatory medications was associated with a decrease in asthma mortality in Japan, the first country to use leukotriene receptor antagonists.

A population-based ecological study was conducted, spanning the period 1987-1999, among people aged 5-34 yrs in Japan. The association between the yearly rate of asthma death and sales of inhaled corticosteroids and leukotriene receptor antagonists was estimated using Poisson regression.

The yearly asthma death rate was stable at 6-7 deaths per million before the introduction of leukotriene receptor antagonists in 1995 and decreased by $23 \%$ thereafter, reaching 3.5 per million in 1999. The rate of asthma death was found to decrease with increasing use of both leukotriene receptor antagonists and inhaled corticosteroids. The rate ratio of asthma death was 0.96 per 1 million 25-day treatment courses of inhaled corticosteroids and 0.80 for every 1 million 25-day treatment courses of leukotriene receptor antagonists, consumed per year in Japan.

The increasing use of inhaled corticosteroids and leukotriene receptor antagonists may have contributed to the significant reduction in asthma mortality among young asthmatics in Japan.

Eur Respir J 2003; 21: 101-104.
From the Division of Clinical Epidemiology, Royal Victoria Hospital, McGill University Health Centre, and the Departments of Epidemiology and Biostatistics and of Medicine, McGill University, Montreal, Canada.

Correspondence: S. Suissa, Division of Clinical Epidemiology, Royal Victoria Hospital, 687 Pine avenue west, Ross 4.29, Montreal, Québec, Canada H3A $1 \mathrm{~A} 1$.

Fax: 15148431493

E-mail: samy.suissa@clinepi.mcgill.ca

Keywords: Asthma, epidemiological studies, inhaled glucocorticoids, leukotriene receptor antagonist, mortality, secular trends

Received: July 42002

Accepted after revision: August 212002

This study was funded by grants from the Canadian Institutes of Health Research (CIHR) and the Fonds de la recherche en santé du Québec. S. Suissa is the recipient of a Distinguished Senior Scientist award from the CIHR.
The recognition of airway inflammation in asthma, present even among subjects with mild intermittent disease, has led to the development of two classes of anti-inflammatory medications. Inhaled corticosteroids, introduced in the 1970 s to reduce the need for oral corticosteroids in patients with severe asthma, were subsequently found to be effective in controlling the symptoms of asthma, reducing airway inflammation and hyperresponsiveness [1]. National guidelines recommended their use as first-line therapy in the treatment of moderate-to-severe asthma in adults $[2,3]$. Their effectiveness was confirmed by clinical trials, while recent large epidemiological studies have demonstrated their ability to prevent major asthma outcomes, such as asthma hospitalisation, near-fatal and fatal asthma [4-6], and to be associated with reductions in asthma mortality in several countries [7-9].

Leukotriene receptor antagonists (LTRAs), on the other hand, were introduced only recently as a new class of medications for the treatment of asthma [10]. These nonsteroidal anti-inflammatory medications are currently recommended in North America as maintenance therapy for the treatment of mild persistent asthma and as add-on therapy to inhaled corticosteroids in moderate asthma [11]. They have been shown to improve lung function and even to reduce healthcare contacts and absenteeism [10, 12]. However, the clinical studies on the effectiveness of these medications were all short term and based on limited sample sizes. In 1995, Japan became the first country worldwide to introduce a LTRA, namely pranlukast, to the market. Other agents of this class, namely zafirlukast and montelukast followed later in Europe and North America. At this point, and in contrast with inhaled corticosteroids, population-based studies have yet to be conducted to assess the impact of these medications on important asthma outcomes such as morbidity or mortality. Japan offers a unique opportunity to evaluate the impact of both classes of antiinflammatory medications.

This study assessed whether the increasing use of inhaled corticosteroids and LTRAs was associated with a decrease in asthma mortality in Japan, the only country with a sufficiently long period of experience with both classes of anti-inflammatory drugs.

\section{Study design}

\section{Methods}

First a secular trend approach was used to study the rate of asthma death and to verify whether this rate 
shifted at the time of introduction of LTRAs in Japan. To assess this change, asthma death rates were computed yearly for the period 1987-1999, and the rates of the pre-LTRA (1987-1994) and intra-LTRA (1995-1999) periods were compared. An ecological design was also used to correlate the yearly consumption of inhaled corticosteroids and leukotriene receptor antagonists with asthma mortality in Japan during this period.

\section{Data and measurements}

Yearly data on the size of the population and on the number of asthma deaths in people aged 5-34 yrs were obtained directly from Japanese vital statistics, supplied by the Department of the Ministry of Health and Welfare of Japan. Monthly data on sales of asthma medications were obtained from IMS Health Japanese Pharmaceutical Market data. LTRA sales were measured in units of 100 million capsules of $112.5 \mathrm{mg}$ of pranlukast, which corresponds to 1 million 25-day courses of this medication at the dose of $225 \mathrm{mg}$ b.i.d. recommended in Japan. Inhaled corticosteroid consumption was also measured in units of 1 million 25-day courses of therapy. The large majority of beclomethasone dispensed was low dose, that is $50 \mu \mathrm{g}$ per inhalation from a metered dose inhaler or $100 \mu \mathrm{g}$ as a dry powder at one or two inhalations four times per day. There was very little use of higher concentrations of beclomethasone. Fluticasone was introduced in late 1998 as a dry powder and use was recommended as one inhalation b.i.d. so that each unit dispensed would also last $\sim 25$ days.

\section{Data analysis}

Poisson regression models were used for all analyses. For the secular trend analysis, a loglinear Poisson model was used to estimate the rate ratio of asthma death between the pre- and intra-LTRA eras. To correlate yearly drug consumption with the corresponding yearly rate of asthma death a loglinear relative risk model was fit to estimate rate ratios and a linear excess risk model was used to estimate rate differences associated with LTRAs and inhaled corticosteroid usage [13]. All models included an adjustment for extraPoisson year-to-year variability. Confidence intervals (CI) were computed at the $95 \%$ level.

\section{Results}

Table 1 summarises the yearly rate of asthma death, along with the yearly consumption of inhaled corticosteroids and LTRAs, separately for the pre- and intra-LTRA periods. The yearly asthma death rate for people aged 5-34 yrs during the period 1987-1999 is displayed in figures 1 and 2 . It indicates a stable mortality rate of 6-7 deaths per million per year prior to the introduction of LTRA (1987-1994). There was
Table 1.-Distribution of yearly death rates among subjects aged 5-34 yrs and drug sales in Japan during the 13-yr period 1987-1999

Period of introduction of LTRAs

\begin{tabular}{cc}
\hline $\begin{array}{c}\text { Before } \\
(1987-1994)\end{array}$ & $\begin{array}{c}\text { After } \\
(1995-1999)\end{array}$ \\
8 & 5 \\
6.64 & 5.14 \\
$6.39-6.89$ & $4.85-5.43$ \\
$2.97 \pm 1.21$ & $8.72 \pm 1.46$ \\
0 & $1.44 \pm 0.71$ \\
\hline
\end{tabular}

Data are presented as mean \pm SD unless otherwise stated. LTRAs: leukotriene receptor antagonists; CI: confidence interval. " : sales per year in units of 1 million 25-day treatment courses of inhaled corticosteroids; ${ }^{\uparrow}$ : sales per year in units of 1 million 25-day treatment courses of LTRAs.

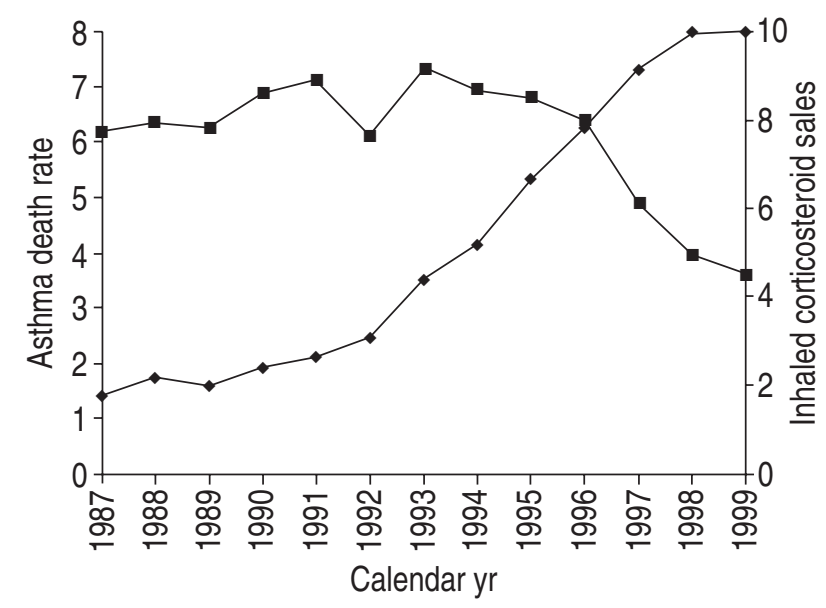

Fig. 1.- Yearly asthma death rate per million people aged 534 yrs in Japan over the period 1987-1999 (口) along with sales of inhaled corticosteroids in units of 1 million 25-day treatment courses $(\bullet)$.

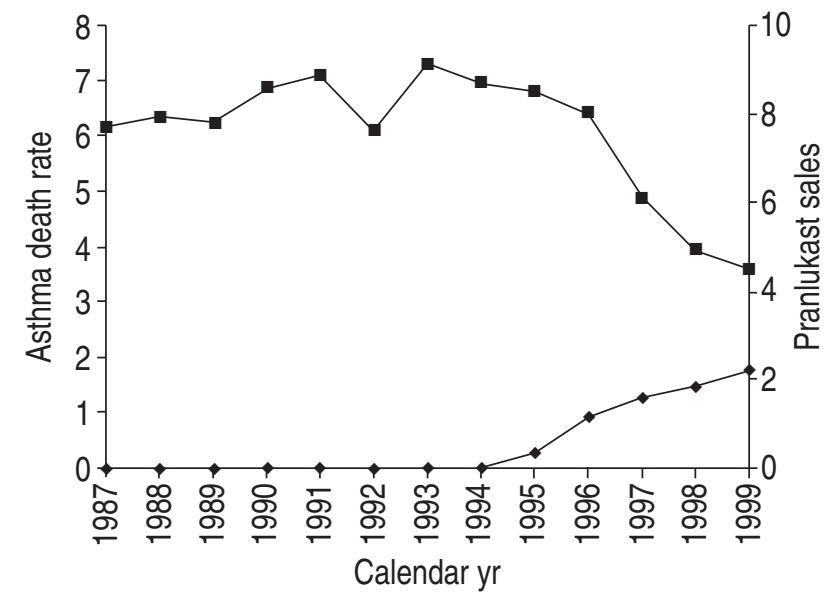

Fig. 2.- Yearly asthma death rate per million people aged 534 yrs in Japan over the period 1987-1999 (ם) along with sales of leukotriene receptor antagonists in units of 1 million treatment episodes of 25 days with capsules of $112.5 \mathrm{mg}$ of pranlukast $(\bullet)$. 
a substantial decrease from 1995 reaching $\sim 3.5$ per million by 1999 . The rate ratio for the intra-LTRA period relative to the pre-LTRA period was 0.77 (23\% reduction in the rate of asthma death; $95 \%$ CI $17-27 \%$ ). This decrease corresponds to a reduction of 1.5 deaths per million per year after this introduction.

Figures 1 and 2 display the yearly asthma death rate per million with the corresponding inhaled corticosteroid and LTRA sales, respectively, for the period 1987-1999. They indicate that while the mean asthma death rate decreased from $>6$ to $\sim 3.5$ per million per year, the consumption of inhaled corticosteroids and LTRAs was increasing substantially.

Table 2 shows that the rate ratios of asthma death were 0.96 (95\% CI: 0.95-0.97) for every 1 million 25-day treatment courses of inhaled corticosteroids sold per year and 0.80 (95\% CI: $0.76-0.83)$ for every 1 million 25-day treatment courses of LTRAs sold per year. Table 2 also indicates that every additional 1 million treatment courses of LTRAs is associated with a reduction of 1.29 asthma deaths per million people per year and that every additional million units of inhaled corticosteroid is associated with a reduction of 0.29 asthma deaths per million people per year. These reductions translate to the prevention of 15-65 asthma deaths per year among the entire Japanese population of this age group.

\section{Discussion}

The present study observed that a significant reduction in asthma mortality has been gradually occurring in Japan since 1995, with as much as a $50 \%$ reduction by 1999. The findings suggest that this considerable reduction in asthma mortality may have resulted from the temporally associated increase in the consumption of anti-inflammatory medications, namely inhaled corticosteroids and LTRAs. The asthma death rate, which had been stable for a decade, started to decline substantially with the coincident introduction of the first LTRA in Japan in 1995, as well as the continued increase in inhaled corticosteroid consumption which appears to have started $\sim 5$ yrs earlier but accelerated after 1992. In addition, the gradient of decline in asthma death was significantly associated with both the quantity of LTRAs consumed and the increasing

Table 2. - Rate ratio and rate difference of asthma death, among subjects aged 5-34 yrs in Japan during 19871999, associated with leukotriene receptor antagonist (LTRA) and inhaled corticosteroid use

\begin{tabular}{lcccc}
\hline & $\mathrm{RR}^{\#}$ & $95 \% \mathrm{CI}$ & $\mathrm{RD}^{\oplus}$ & $95 \% \mathrm{CI}$ \\
\hline $\begin{array}{l}\text { Inhaled corticosteroids } \\
\begin{array}{l}\text { Leukotriene receptor } \\
\text { antagonists }\end{array}\end{array}$ & 0.96 & $0.95-0.97$ & -0.29 & $-0.35-0.23$ \\
\hline
\end{tabular}

$\mathrm{RR}$ : rate ratio; $\mathrm{RD}$ : rate difference; $\mathrm{CI}$ : confidence interval; \#: RR of asthma death per additional 1 million 25-day treatment courses of inhaled corticosteroids or LTRAs; ${ }^{\top}$ : RD of asthma deaths per million people per year associated with every additional 1 million 25-day treatment courses of inhaled corticosteroids or LTRAs. consumption of inhaled corticosteroids during this same period.

These results must be interpreted with caution. Population-based epidemiological studies based on ecological designs are inherently weak because they fail to make a direct individual connection between the subjects who were exposed, in this case asthmatics using a specific medication, and those who experienced the outcome, in this case asthmatics who die. The "ecological fallacy" can result from this limitation and that is why ecological studies are employed primarily to generate hypotheses. For example, the time trends observed for asthma mortality might also be the result of the increasing awareness of asthma guidelines (revised version of the Japanese guidelines was published in 1995 [14]) and their recommendations by physicians. These guidelines not only recommend greater use of anti-inflammatory medications, but also make recommendations on diagnosis and the importance of asthma education [15]. Nevertheless, the ecological study design can be a useful and valid approach to assess the intended effects of interventions at the population level. Indeed, this same ecological study design was used to indicate a protective effect of inhaled corticosteroids on asthma mortality in New Zealand, the UK and Israel [7-9]. This prophylactic effect of inhaled corticosteroids on asthma death was recently confirmed in a case-control study [6].

While the effect of inhaled corticosteroids on asthma mortality was expected from the multitude of previous studies from other countries, the findings on LTRAs are novel. An alternative explanation to the important reduction in asthma mortality that started in 1995 may be the wider and perhaps more regular use of inhaled corticosteroids in that country. It is possible that the use of these drugs prior to 1995, although increasing, was insufficient or inappropriate to impact on asthma mortality. This is plausible since recent studies indicate that only regular inhaled corticosteroid use is effective at reducing major outcomes [16]. In the present study, it was not possible to separate the effects of inhaled corticosteroid consumption from that of LTRA consumption on asthma mortality. The strong correlation between the consumption of these two medications and the limited number of years of use of LTRAs made it practically impossible to assess their independent effects. Nevertheless, the sharpest decrease in asthma mortality did follow the introduction of LTRAs in that country. Whether this class of medication played a role in this decline cannot be confirmed but can certainly be hypothesised on the basis of these data. Epidemiological studies based on individual subjects will need to be conducted to substantiate the effectiveness of LTRAs in preventing asthma death and, in particular, to verify whether the effect is independent of inhaled corticosteroid use.

In all, this study adds to the evidence on the prevention of asthma death with anti-inflammatory treatment in general, including inhaled corticosteroids, and now possibly with the new class of leukotriene receptor antagonists. This latter observation must be studied further with more rigorous cohort and case-control studies. 
Acknowledgements. The authors would like to thank C. Schjuit of Boehringer-Ingelheim for assistance in obtaining the data.

\section{References}

1. Barnes PJ. Current issues for establishing inhaled corticosteroids as the antiinflammatory agents of choice in asthma. J Allergy Clin Immunol 1998; 101: S427-S433.

2. National Asthma Education Program National Heart, Lung, and Blood Institute. Guidelines for the diagnosis and management of asthma. Publication No. 91-3042. Bethesda, MD, National Institutes of Health, 1991; pp. 1-135.

3. Hargreave FE, Dolovich J, Newhouse MT. The assessment and treatment of asthma: a conference report. J Allergy Clin Immunol 1990; 85: 1098-1111.

4. Blais L, Ernst P, Boivin JF, et al. Am J Respir Crit Care Med 1998; 158: 126-132.

5. Ernst P, Spitzer WO, Suissa S, et al. Risk of fatal and near-fatal asthma in relation to inhaled corticosteroid use. JAMA 1992; 268: 3462-3464.

6. Suissa S, Ernst P, Benayoun B, Baltzan M, Cai B. Low-dose inhaled corticosteroids and the prevention of death from asthma. N Engl J Med 2000; 343: 332-336.

7. Devoy MA, Fuller RW, Palmer JB. Asthma mortality and beta-agonists. Chest 1995; 108: 1768.

8. Suissa S, Ernst P. Optical illusions from visual data analysis: example of the New Zealand asthma mortality epidemic. $J$ Clin Epidemiol 1997; 50: 1079-1088.

9. Goldman M, Rachmiel M, Gendler L, Katz Y. Decrease in asthma mortality rate in Israel from 1991-1995: is it related to increased use of inhaled corticosteroids? J Allergy Clin Immunol 2000; 105: 71-74.

10. Lipworth BJ. Leukotriene-receptor antagonists. Lancet 1999; 353: 57-62.

11. National Asthma and Prevention Program. Guidelines for the diagnosis and management of asthma. Expert Panel Report 2. Publication No. 97-4051. Bethesda, MD, USA, National Institutes of Health, 1997.

12. Suissa S, Dennis R, Ernst P, Sheehy O, WoodDauphinee S. Effectiveness of the leukotriene receptor antagonist zafirlukast for mild-to-moderate asthma. A randomized, double-blind, placebo-controlled trial. Ann Intern Med 1997; 126: 177-183.

13. Generalized Linear Models. 2nd edn. London, Chapman and Hall, 1989.

14. Makino S, Miyamoto T, Nakajima S, et al. Survey of recognition and utilization of guidelines for the diagnosis and management of bronchial asthma in Japan. Allergy 2000; 55: 135-140.

15. Makino SFK, Miyamoto T, Ohta K. Asthma prevention and management guidelines. Int Arch Allergy Immunol 2000; 121: Suppl. 1.

16. Suissa S, Ernst P. Inhaled corticosteroids: impact on asthma morbidity and mortality. J Allergy Clin Immunol 2001; 107: 937-944. 